\title{
Interleukin-10 may protect against progressing injury during the acute phase of ischemic stroke
} Interleucinas 1B, 2 e 10 e prognóstico neurológico durante a fase aguda do AVC isquêmico

\author{
Gustavo G. Protti', Rubens J. Gagliardi², Wilma C. N. Forte ${ }^{3}$, Sandra Regina S. Sprovieri ${ }^{4}$
}

\begin{abstract}
Atherosclerosis is an inflammatory disease, and ischemic stroke is one of its most common and devastating manifestations. Proinflammatory cytokines play a key role in the progression of the irreversible ischemic lesions. The presence of anti-inflammatory mediators may prevent secondary ischemic injury. Objectives: 1) To assess the relationship between stroke severity and the serum levels of IL-1 $\beta$, IL-2, and IL-10; and 2) To analyze the neurological outcome after $72 \mathrm{~h}$ of ischemic stroke onset and expression of interleukins. Method: We measured the serum levels of IL-1 $\beta$, IL-2, and IL-10 in 26 patients with acute stroke. Neurological impairment was scored using the National Institute of Health Stroke Scale within the first $72 \mathrm{~h}$ after stroke onset. Thirty healthy subjects were analyzed as controls. Results: Patients with IL-10 $<925.0 \mathrm{pg} / \mathrm{mL}$ presented with neurological deterioration within the first $72 \mathrm{~h}$. Conclusion: IL-10 may protect against ischemic injury during the acute phase of stroke.
\end{abstract}

Keywords: ischemic stroke, cytokines, inflammation.

\section{RESUMO}

Aterosclerose é considerada um doença inflamatória e o acidente vascular cerebral (AVC) isquêmico uma de suas principais manifestações. Citocinas pró-inflamatórias exercem importante função na progressão para uma lesão isquêmica irreversível. A presença de mediadores anti-inflamatórios age prevenindo a lesão isquêmica secundária. Objetivos: 1) Avaliar a relação entre gravidade do AVC e níveis de IL-1 $\beta$, IL-2 e IL-10; 2) Avaliar a relação entre prognóstico neurológico nas primeiras 72 horas do AVC e o nível destas citocinas. Método: Mensuramos os níveis de IL-1 $\beta$, IL-2 e IL-10 de 26 pacientes com AVC isquêmico. O comprometimento neurológico foi avaliado através da escala do National Institute of Health nas primeiras 72 horas do AVC. Trinta indivíduos saudáveis foram usados como controles. Resultados: Pacientes com IL-10 <925,0 pg/mL apresentaram deterioração neurológica nas primeiras 72 horas após o início do AVC. Conclusão: IL-10 pode apresentar um efeito protetor contra a progresso da lesão isquêmica durante a fase aguda do AVC.

Palavras-chave: acidente vascular cerebral isquêmico, citocinas, inflamação.

Stroke is a frequent cause of death and long-term disability worldwide. One-third of the patients with acute ischemic stroke develop early neurological defects, resulting in increased mortality and functional disability ${ }^{1}$. The underlying mechanism is not completely understood, but there is evidence pointing toward the role of inflammation in acute stroke progression. Peripheral leukocyte influx into the ischemic cerebral parenchyma and activation of microglia occur during the first few hours after stroke onset. The activated cells secrete cytokines resulting in a local upregulation of adhesion molecules and further recruitment of peripheral leukocytes, thereby amplifying the inflammatory response trigged by ischemia ${ }^{2}$.
Neutrophils are generally the first leukocyte sub-type recruited to ischemic cerebral tissue, followed by lymphocytes. Both neutrophils and lymphocytes secrete potentially cytotoxic substances, such as inflammatory mediators and proteolytic enzymes, involved in secondary tissue damage among the penumbra surrounding the infarct core ${ }^{2}$. Leukocyte recruitment and adhesion to cerebral endothelium also obstruct the microvessels within the penumbra and contribute to the impairment of complete reperfusion of the ischemic brain tissue ${ }^{3}$.

Expression of proinflammatory cytokines was detected in early atherogenesis, atheroma formation, and thrombosis,

\footnotetext{
Faculty of Medical Sciences, Irmandade da Santa Casa de Misericórdia de São Paulo, São Paulo, Brazil.

${ }^{1}$ Neurologist of the Emergency Service, Department of Medicine;

${ }^{2}$ Full Professor of the Neurology Division, Department of Medicine;

${ }^{3}$ Professor of the Immunology Division, Department of Pathological Sciences;

${ }^{4}$ Clinical Coordinator of the Emergency Service and Discipline Leader Emergency Medicine, Department of Medicine;

Correspondence: Rubens José Gagliardi; Rua Dr. Cezário Motta Jr.112; Vila Buarque; 01221-020 São Paulo SP - Brasil; E-mail: rubensjg@apm.org.br

Conflict of interest: There is no conflict of interest to declare.

Received 18 October 2012; Received in final form 26 June 2013; Accepted 04 July 2013.
} 
the last complication of atherosclerosis responsible for myocardial infarction and most strokes ${ }^{4}$. Moreover, these inflammatory mediators are considered to be responsible for recruiting leukocytes to the ischemic area after stroke ${ }^{5}$.

Interleukin 1 (IL-1) is the prototypic inflammatory cytokine with widespread impact on neural function. IL-1 family cytokines consist of six members, three receptor ligands [IL-1a, IL-1 $\beta$, and IL-1 receptor antagonist (IL-1ra)], two receptor subtypes (IL-1RI and IL-1RII), and an accessory protein (IL-1AcP). The IL-1 family inflammatory mediators show cell-specific patterns of production, expression, and release. Ligands are primarily produced by glia (and some neurons), while astrocytes and neurons express the signal transducing receptor IL-1RI'. Under normal conditions, IL-1 expression is very low in the brain ${ }^{6}$; however, IL-1 $\beta$ expression is rapidly induced in stroke models. It has been shown that rats expressing low serum levels of IL-1 exhibit lesser extent of ischemic injury following transient or permanent middle cerebral artery (MCA) occlusion, suggesting that IL-1 may play a deleterious role in cerebral ischemia. Similarly, administration of IL-1ra or Il-1 $\beta$ blocking antibodies has been shown to reduce neuronal death. On the other hand, administration of recombinant IL- $1 \beta$ is associated with larger lesions, brain edema, and neutrophil adhesion and infiltration within the ischemic tissue. Furthermore, IL-1 also regulates the expression of the endothelial cell adhesion molecules, and promotes the neutrophil tissue infiltration. In addition, IL-1 induces the production of other cytokines, such as IL-6, TNF- $\alpha$, CSFs and itself, in a positive feedback loop, thereby making it difficult to distinguish the IL-1-specific effects compared with the indirect effects from other cytokines ${ }^{2}$.

IL-10, an anti-inflammatory cytokine inhibits the production of IL-1 and TNF- $\alpha$ by suppressing cytokine receptor expression and activation. IL-10 is synthesized in the central nervous system (CNS) and is upregulated in stroke models. Exogenous expression of IL-10 or IL-10 gene transfer are associated with reduced ischemic area after MCA occlusion, suggesting a protective role for IL-10 against ischemic injury². Furthermore, subjects with low peripheral serum levels of IL-10 have an increased risk for stroke ${ }^{7}$. Low serum levels of IL-10 have also been associated with unstable clinical progression in angina patients 8 .

Interleukin-2 (IL-2), the cytokine also known as T-cell growth factor, is involved in several immunoregulatory and biological functions not only related to the T-cells. IL-2 is known to regulate several processes in CNS, such as sleep and arousal, memory function, and locomotion and the modulation of the neuroendocrine axis. IL-2 and/or IL-2R have been shown to be expressed in rodent and human frontal cortex, septum, striatum, hippocampal formation, hypothalamus, locus coeruleus, cerebellum, and the pituitary and fiber tracts such as the corpus callosum. Due to its blood-brain barrier permeability, IL-2 from either peripheral or central origin, can access the functional IL-2R molecules on neurons and glia ${ }^{9}$. Therefore, IL-2 may play a key role in the pathogenesis of stroke either by promoting T-cell recruitent or by its direct action upon the neurons and glia cells.

\section{PURPOSE}

In view of this issue, we evaluated the relationship between IL-1 $\beta$, IL-2, and IL-10 expression and neurologic outcome following $72 \mathrm{~h}$ of ischemic stroke onset. Serum levels of IL-1 $\beta$, IL-2, and IL- 10 of patients with acute stroke were compared with those of controls classified as having significant atherosclerosis.

\section{METHOD}

\section{Patients and control subjects}

In brief, all the subjects were over 18 years and from Santa Casa de Misericórdia de São Paulo. Subjects within 72 h of acute ischemic stroke onset were integrated in to the group 1. Subjects were selected on Monday, Tuesday, and Wednesday, between June 2005 and December 2006. Subjects with known chronic inflammatory or infectious disease, cancer, hematologic disease and renal or hepatic insufficiency were excluded from the study. Patients where time of symptom onset could not be reliably determined were also excluded. Group 2 composed of control subjects with no history of stroke or transient ischemic attack, infectious or inflammatory disease, malignances or renal or hepatic failure. Control subjects had at least two risk factors for atherosclerosis ${ }^{10}$ at the time of inclusion in this study and were under regular follow-up at the geriatric ambulatory of the D. Pedro II Hospital, maintained by Santa Casa de Misericórdia de São Paulo. Written informed consent of approval was obtained from all the patients and control subjects. This study had the approval of the Local Research Ethics Committee.

Diagnosis of ischemic stroke was based on the clinical features. Computed tomography (CT) scans of brains were performed within $24 \mathrm{~h}$ of admission, to exclude the patients with primary intracerebral hemorrhage and other strokemimicking conditions. To evaluate the degree of atherosclerosis, bedside carotid ultrasound was performed on patients and control subjects with conditions that allowed the examination; because this facility was not available at the hospital, it was conducted at the radiology department ${ }^{11}$. Patients and control subjects evaluated by carotid ultrasound were classified into two subgroups, one without significant atherosclerosis (bilateral, $<50 \%$ carotid artery stenosis) and the other with significant atherosclerosis $(\geq 50 \%$ carotid artery stenosis on at least one side). 


\section{Clinical outcome assessment}

The severity of neurological impairment was evaluated and scored by the National Institutes of Health Stroke Scale (NIHSS, referred to as $\mathrm{NIH}_{1}$ ). A new neurological examination was performed after $72 \mathrm{~h}$ of stroke onset. The neurological deficit and functional disability were scored by the NIHSS (referred to as $\mathrm{NIH}_{2}$ ) and the modified Rankin Scale (mRS) respectively. Neurological outcome evaluation was based on the NIHSS score variation $\left(\mathrm{NIH}_{1}-\mathrm{NIH}_{2}\right)$ and the mRS score. For the purpose of stratifying into different outcome subgroups, patients were further classified into the better $\left(\mathrm{NIH}_{2} \leq \mathrm{NIH}_{1}\right)$ or worse $\left(\mathrm{NIH}_{2}>\mathrm{NIH}_{1}\right)$ outcome groups.

\section{Blood samples}

At baseline, venous blood samples were collected from patients and control subjects into tubes containing heparin. Thirty minutes after collection, $30 \mathrm{~mL}$ of blood was centrifuged in Ficoll-Paque (Pharmacia ${ }^{\mathrm{TM}}$ ) gradient (300 g, 30 min, room temperature). Cell pellets were washed twice with sterile Roswell Park Memorial Institute-1640 medium (RPMI, Cultilab") (300 g, $10 \mathrm{~min}, 4^{\circ} \mathrm{C}$ ) and resuspended in RPMI-1640 medium supplemented with $10 \%$ fetal bovine serum (FBS), L-glutamine [2 mM], and gentamicine [ $5 \mathrm{\mu g} / \mathrm{mL}]$. Cell number was adjusted to $1 \times 10^{6} \mathrm{cell} / \mathrm{mL}$ and stimulated with phytohemagglutinin for $48 \mathrm{~h}, 37^{\circ} \mathrm{C}, 5 \% \mathrm{CO}_{2}$ atmosphere. Cell culture supernatants were aliquoted and stored at $-70^{\circ} \mathrm{C}$ until analysis.

\section{Immunological Assays}

Blood culture supernatants were assayed for the serum levels of IL-1 $1 \beta$, IL-2, and IL-10 by using the commercial kits for quantitative enzyme-linked immunosorbent assay (ELISA) supplied by BD Biosciences $\left(O p t E I A^{\mathrm{TM}}\right)$. Assay sensitivities were $7.8 \mathrm{pg} / \mathrm{mL}$ minimum and $500 \mathrm{pg} / \mathrm{mL}$ maximum. Samples were diluted to 1:10 to achieve maximum allowed sensitivity of $5000 \mathrm{pg} / \mathrm{mL}$. Values over $5000 \mathrm{pg} / \mathrm{mL}$ were estimated using the linear coefficient 0.9979. Analyses were performed by technician's blind to clinical information.

\section{Statistical Analysis}

The $\chi 2$ and Student $t$-tests were first applied for "gender" and "age" variable assessment. Clinical data (mRS and NIHSS) and cytokine levels were not normally distributed. Analyses were performed using the Statistical Package for Social Sciences software (SPSS v13.0), considering a p-value $<5 \%$ as significant. Difference in cytokine levels between the two groups was assessed using the Mann-Whitney test. The Spearman correlation analysis was applied to verify the possible relationship between cytokine levels and stroke severity $\left(\mathrm{NIH}_{1}\right)$. Finally, the Mann-Whitney test was again applied on group 1 to compare the cytokine levels on admission and neurological impairment progression (mRS and $\mathrm{NIH}_{2}$ ). The receiver-operating characteristic (ROC) curve analysis was applied on significant cytokine data to determine the cutoff values in group 1 patients.

\section{RESULTS}

Eighty-seven patients were recruited in group 1. Sixty-one patients were excluded due to one or more of the following criteria: 32 could not sign the written informed consent, 53 could not define the exact time of symptoms onset, 3 patients had a diagnosis of cancer, and 6 presented evidence of active malignancy during the first few days after admission. Therefore, only 26 patients [ 14 women and 12 men, mean age $65.54( \pm 12.54)$ years] were eligible to remain in the group 1 . According to Toast ${ }^{11}, 13$ patients were classified as probable, and 5 as possible toward large-artery atherosclerosis stroke, 4 for small-vessel occlusion (lacune), and 4 for cardioembolism. The mean time between stroke onset and blood sample collection was 22.85 (7-49) h. Group 2 composed of 30 consecutive control subjects [ 23 women and 7 men, mean age $73.06( \pm 10.63)$ years]. Participant characteristics are summarized in Tables 1 and 2.

Among the patients evaluated with carotid ultrasound, there was a significant $(p=0.016)$ predominance of highgrade atherosclerosis within the stroke patients compared to the control subjects. There were no significant differences in IL-1 $\beta$, IL-2, and IL-10 levels between groups 1 and 2 ( $p=0.479$, 0.370 , and 0.805 , respectively, Figure 1). Neurologic impairment severity on admission had no correlation with the cytokines tested ( $p=0.919,0.053$, and 0.493 for IL-1 $\beta$, IL-2, and IL10 respectively). IL-1 $\beta$ and IL-2 levels were not significantly altered with either better or worse outcomes ( $p=0.073$ and 0.648 , respectively, Figure 2). On the other hand, a significant increase in IL-10 level was associated $(p=0.040)$ with neurological improvement following $72 \mathrm{~h}$ of stroke onset (better outcome subgroup patients). From ROC curve analysis, the IL-10 cutoff value of $925.0 \mathrm{pg} / \mathrm{mL}$ is associated with the best sensitivity and specificity (76.2\% and $80 \%$ respectively) (Figure 2). Therefore, patients with an IL-10 value above the $925.0 \mathrm{pg} / \mathrm{mL}$ cutoff tend to have a better outcome after $72 \mathrm{~h}$.

\section{DISCUSSION}

The immune activity in the healthy central nervous system (CNS) is tightly regulated to prevent unwanted immunemediated damage ${ }^{12}$. Cytokines such as IL-1, IL-2, and IL-10 are key regulators of immune activity at the sites of infection or tissue damage. To produce cytokines, source cells such as macrophages, monocytes, lymphocytes, endothelial cells, platelets, astrocytes, microglia, and neurons must be activated. Acute ischemia may play a role in cell activation for cytokine production within the brain ${ }^{13}$. 
Table 1. Main characteristics of patients with acute ischemic stroke (group 1).

\begin{tabular}{|c|c|c|c|c|c|c|c|c|c|c|c|}
\hline No & Gender & $\begin{array}{c}\text { Age } \\
\text { (years) }\end{array}$ & Risk factors & Toast & $\begin{array}{c}\text { Atherosclerosis } \\
\text { degree }^{*}\end{array}$ & $\mathrm{NIH}(1)$ & $\begin{array}{l}\text { Time } \\
\text { (h) }\end{array}$ & $\mathrm{IL}-1 \beta^{* \star}$ & $\mathrm{IL}-2^{\star \star}$ & IL-10** & $\mathrm{NIH}(2)$ \\
\hline \multicolumn{12}{|c|}{ Improvement in NIHSS after $72 \mathrm{~h}$ of stroke onset } \\
\hline 1 & $\mathrm{~F}$ & 68 & $\mathrm{O}, \mathrm{HTN}$ & $1 \mathrm{~A}$ & $<50 \%$ & 14 & 24 & 5132.00 & 1603.66 & 2453.61 & 10 \\
\hline 8 & M & 67 & HTN, DM & $1 \mathrm{~A}$ & $<50 \%$ & 06 & 24 & 1165.98 & 1762.76 & 2395.56 & 01 \\
\hline 16 & M & 59 & HTN, Sm & $1 \mathrm{~A}$ & NA & 09 & 30 & 2185.00 & 4004.08 & 2683.00 & 03 \\
\hline 19 & $M$ & 59 & Sm, HTN & $1 \mathrm{~A}$ & $<50 \%$ & 11 & 48 & 853.965 & 5963.35 & 3151.14 & 00 \\
\hline 20 & F & 46 & Sm, S & $1 \mathrm{~A}$ & NA & 03 & 18 & 529.84 & 739.28 & 2231.60 & 01 \\
\hline 21 & F & 74 & S, HTN & $1 \mathrm{~A}$ & NA & 07 & 21 & 2213.78 & 1245.90 & 1286.65 & 06 \\
\hline 24 & F & 75 & HTN, C, St & $1 \mathrm{~A}$ & $<50 \%$ & 08 & 18 & 5535.05 & 2187.00 & 3151.14 & 06 \\
\hline \multicolumn{12}{|c|}{ NIHSS unchanged after $72 \mathrm{~h}$ of stroke onset } \\
\hline 2 & M & 77 & $\mathrm{C}, \mathrm{TIA}, \mathrm{HT}, \mathrm{HTN}$ & $1 \mathrm{~A}$ & $<50 \%$ & 04 & 16 & 3401.45 & 5963.35 & 3151.14 & 04 \\
\hline 3 & M & 51 & HTN, Sm, PAD & $1 \mathrm{~B}$ & $50-69 \%$ & 12 & 16 & 712.91 & 1384.88 & 2534.07 & 12 \\
\hline 4 & F & 31 & PFO, TG, Sm, S & 3 & no stenosis & 04 & 25 & 635.49 & 5059.56 & 1433.36 & 02 \\
\hline 5 & $\mathrm{~F}$ & 75 & HTN, C, TG & $1 \mathrm{~A}$ & NA & 19 & 16 & 1932.20 & $<7.80$ & 457.10 & 19 \\
\hline 7 & M & 61 & $\mathrm{TG}, \mathrm{O}$ & $1 \mathrm{~A}$ & NA & 36 & 22 & 4104.66 & 1378.75 & 632.28 & 36 \\
\hline 10 & M & 64 & HTN, DM, SmT & 2 & NA & 03 & 24 & 1669.38 & 2237.23 & 1045.50 & 03 \\
\hline 12 & M & 80 & HTN, O & 2 & $<50 \%$ & 04 & 17 & 3288.61 & 615.81 & 1842.72 & 04 \\
\hline 13 & F & 75 & HTN, S & 2 & no stenosis & 04 & 20 & 485.27 & 1710.48 & 1241.41 & 04 \\
\hline 15 & F & 84 & $\mathrm{HTN}, \mathrm{Ac}, \mathrm{CHF}$ & 3 & NA & 36 & 7 & $<7.80$ & $<7.80$ & $<7.80$ & 36 \\
\hline 17 & M & 67 & HTN, St & $1 \mathrm{~B}$ & $50-69 \%$ & 07 & 22 & 307.165 & 5963.35 & 3151.14 & 07 \\
\hline 18 & M & 63 & $D M, S$ & $1 \mathrm{~A}$ & $<50 \%$ & 06 & 21 & $<7.80$ & 1121.22 & 490.44 & 06 \\
\hline 22 & F & 81 & Ac, HTN, S & 3 & NA & 19 & 39 & $<7.80$ & 78.86 & 178.625 & 19 \\
\hline 23 & $\mathrm{~F}$ & 58 & DM, HTN, C, S & $1 \mathrm{~B}$ & $50-69 \%$ & 05 & 24 & 1531.23 & 4434.39 & 1778.73 & 05 \\
\hline 26 & $\mathrm{~F}$ & 57 & HTN, DM, MI & $1 \mathrm{~A}$ & $<50 \%$ & 09 & 24 & 1482.14 & 1984.20 & 1162.46 & 09 \\
\hline \multicolumn{12}{|c|}{ Worsening in NIHSS after $72 \mathrm{~h}$ of stroke onset } \\
\hline 6 & $\mathrm{~F}$ & 70 & HTN, DM, St & $1 \mathrm{~B}$ & $50-69 \%$ & 11 & 13 & 3670.53 & 1144.92 & 165.75 & 15 \\
\hline 9 & M & 61 & $\mathrm{Sm}, \mathrm{TG}$ & 2 & NA & 04 & 24 & 975.02 & 2086.29 & 802.61 & 06 \\
\hline 11 & F & 51 & HTN, Sm, S & $1 \mathrm{~B}$ & $>80 \%$ & 06 & 09 & 5535.05 & $<7.80$ & 161.265 & 12 \\
\hline 14 & M & 64 & Aa, HTN, Sm & 3 & NA & 06 & 48 & 1554.62 & 1157.21 & 1585.91 & 36 \\
\hline 25 & F & 86 & DM, S, O, HTN & $1 \mathrm{~A}$ & $<50 \%$ & 02 & 24 & 5535.05 & 5963.35 & 583.41 & 04 \\
\hline
\end{tabular}

M:F:12:14; Mean age: 65,54 ( $\pm 12,61)$ years.

F: female; M: male;Aa: acute cardiac arrhythmia;Ac: chronic cardiac arrhythmia; PFO: patent foramen ovale; HTN: arterial hypertension; DM: diabetes mellitus; Sm: smoke; C: hypercholesterolemy; TG: hypertrigliricidemy; CHF: chronic heart failure; O: obesity; S: sedentarism; St: previous ischemic stroke; TIA: transient ischemic attack; MI: previous myocardial infarction; HT: controlled hyperthyroidism; PAD: peripheral artery disease; Toast: classification of ischemic stroke according to Toast: $1 \mathrm{~A}$ - possible large vessel stroke (atherothombotic), 1B- probable large vessel stroke (atherothrombotic), 2- small vessel stroke (lacune), 3carioembolic stroke; ${ }^{*}$ atherosclerosis degree: stenosis degree according to carotid ultrasound; NA: not available; ${ }^{* *}$ pg/mL. NIHSS: (referred to NIH $)$ National Institutes of Health Stroke Scale.

However, distinguishing inflammation as a response to ischemic brain injury from an inflammatory trigger for acute stroke is difficult. In our study, cytokine levels in stroke patients did not differ from the control subjects, indicating that the changes in cytokine levels following stroke may in fact reflect a pre-existing situation. It is known that the effect of stroke is strongly influenced by pre-existing inflammatory and infectious conditions. The exclusion of patients with known infectious illnesses could apparently attenuate this bias. However, atherosclerosis as an inflammatory disease might also be expected to contribute to a pre-existing inflammatory state and acts as a confounding factor.

Carotid atherosclerosis is an important mechanism in patients with ischemic stroke or transient attack due to the possibility of intervention by endarterectomy or angioplasty. In combination with the degree of luminal stenosis, non-invasive measure of inflammation and plaque instability would be a useful adjunct method to determine the risk of cerebral ischemic events in selected patients for appropriate clinical or surgical treatment. However, further studies analyzing the long-term follow-up are warranted to investigate this issue.

Possible criticism of the present study includes the relatively small sample size. In addition, the release of cytokines is often time-dependent: a single sample from each patient collected at varied time intervals from 7 to $49 \mathrm{~h}$ can reflect different phases of the biomarker kinetics. The difference in timing of sample collection and the extent of severity of 
Table 2. Main characteristics of control subjects (group 2).

\begin{tabular}{|c|c|c|c|c|c|c|c|}
\hline No & Gender & Age (years) & Risk factors & Atherosclerosis degree ${ }^{*}$ & $\mathrm{IL}-1 \beta^{\star *}$ & $\mathrm{IL}-2^{* *}$ & IL-10** \\
\hline \multicolumn{8}{|c|}{ Low grade atherosclerosis } \\
\hline 1 & F & 82 & Ac, HTN, C & stenosis $<50 \%$ & 5535.05 & 1405.84 & 592.22 \\
\hline 2 & $\mathrm{~F}$ & 69 & HTN, DM & stenosis $<50 \%$ & 5085.05 & 1399.70 & 443.54 \\
\hline 4 & $\mathrm{~F}$ & 64 & $\mathrm{C}, \mathrm{HTN}$ & no stenosis & 1041.85 & 216.67 & 3007.25 \\
\hline 6 & M & 88 & O, TG, C, HTN, DM & stenosis $<50 \%$ & 5535.05 & 540.68 & 1096.26 \\
\hline 9 & $\mathrm{~F}$ & 74 & Ac, HTN, DM, CHF & stenosis $<50 \%$ & 5535.05 & 1200.70 & 3151.14 \\
\hline 11 & $\mathrm{~F}$ & 64 & HTN, Sm & stenosis $<50 \%$ & 5132.00 & $<7.80$ & 2975.83 \\
\hline 12 & M & 59 & HTN, DM, O & no stenosis & 3620.90 & $<7.80$ & 920.24 \\
\hline 13 & M & 43 & Sm, HTN & no stenosis & 3768.80 & 1929.90 & 3151.14 \\
\hline 14 & F & 67 & $\mathrm{Sm}, \mathrm{C}$ & no stenosis & 864.95 & 503.69 & 3151.14 \\
\hline 15 & F & 86 & CHF, HTN, S & stenosis $<50 \%$ & 2746.64 & 46.27 & 2279.51 \\
\hline 16 & F & 84 & HTN, DM & stenosis $<50 \%$ & 1280.47 & 5963.35 & 2343.96 \\
\hline 17 & F & 70 & HTN, C & no stenosis & 1512.96 & 2233.54 & 2546.15 \\
\hline 18 & $F$ & 58 & HTN, DM, C & no stenosis & 1264.99 & 5963.35 & 3007.25 \\
\hline 19 & $F$ & 64 & HTN, C & no stenosis & 498.51 & 4525.93 & 1892.92 \\
\hline 20 & $M$ & 74 & S, Sm, C & no stenosis & 1381.08 & 5347.24 & 258.73 \\
\hline 21 & $F$ & 66 & HTN, TG, C & no stenosis & 1158.57 & 3279.84 & 2276.71 \\
\hline 22 & $\mathrm{~F}$ & 67 & S, C & no stenosis & 41.54 & 622.44 & 1868.34 \\
\hline 23 & M & 72 & $\mathrm{C}, \mathrm{TG}, \mathrm{DM}$ & no stenosis & 76.87 & 3563.91 & 1316.59 \\
\hline 24 & $F$ & 79 & HTN, DM, O & stenosis $<50 \%$ & 245.18 & 5221.68 & 1125.20 \\
\hline 25 & $F$ & 72 & HTN, DM, C, O. & stenosis $<50 \%$ & 199.27 & 2795.64 & 1430.20 \\
\hline 26 & $F$ & 68 & HTN, S, TG & no stenosis & 814.18 & $<7.80$ & 588.96 \\
\hline 27 & $F$ & 69 & HTN, O, C, TG & no stenosis & $<7.80$ & 337.05 & 1018.51 \\
\hline 28 & M & 77 & HTN, C, TG & no stenosis & $<7.80$ & $<7.80$ & 371.74 \\
\hline 29 & $\mathrm{~F}$ & 81 & HTN, C & stenosis $<50 \%$ & 4681.12 & 2051.47 & 1018.51 \\
\hline \multicolumn{8}{|c|}{ High grade atherosclerosis } \\
\hline 5 & $\mathrm{~F}$ & 87 & HTN, DM, C & stenosis $>70 \%$ & 5369.00 & 503.71 & 1122.50 \\
\hline 7 & $\mathrm{~F}$ & 91 & HTN, Ac, DM, CHF & stenosis $50-69 \%$ & 4068.02 & 1036.43 & 1493.87 \\
\hline 8 & M & 89 & CHF, HTN, DM & stenosis $>70 \%$ & 4366.17 & 610.60 & 477.37 \\
\hline 10 & $\mathrm{~F}$ & 77 & DM, HTN & stenosis $50-69 \%$ & 4132.28 & 2755.23 & 3007.25 \\
\hline 30 & $\mathrm{~F}$ & 77 & DM, HTN, C & stenosis $50-69 \%$ & 4626.83 & 3411.61 & 371.74 \\
\hline \multicolumn{8}{|c|}{ Carotid ultrasound not performed } \\
\hline 3 & $\mathrm{~F}$ & 74 & Ac, Sm, C & NA & 5109.45 & $<7.80$ & 324.18 \\
\hline
\end{tabular}

M:F: 7:23; Mean age: 73,06 ( $\pm 10,63)$ years; F: female; M: male; Ac: chronic cardiac arrhythmia; HTN: arterial hypertension; DM: diabetes mellitus; Sm: smoke; C: hypercholesterolemy; TG: hypertrigliricidemy; CHF: chronic heart failure; 0 : obesity; S: sedentarism; ${ }^{*}$ atherosclerosis degree: stenosis degree according to carotid ultrasound; NA: not available; ${ }^{* *} \mathrm{pg} / \mathrm{mL}$.

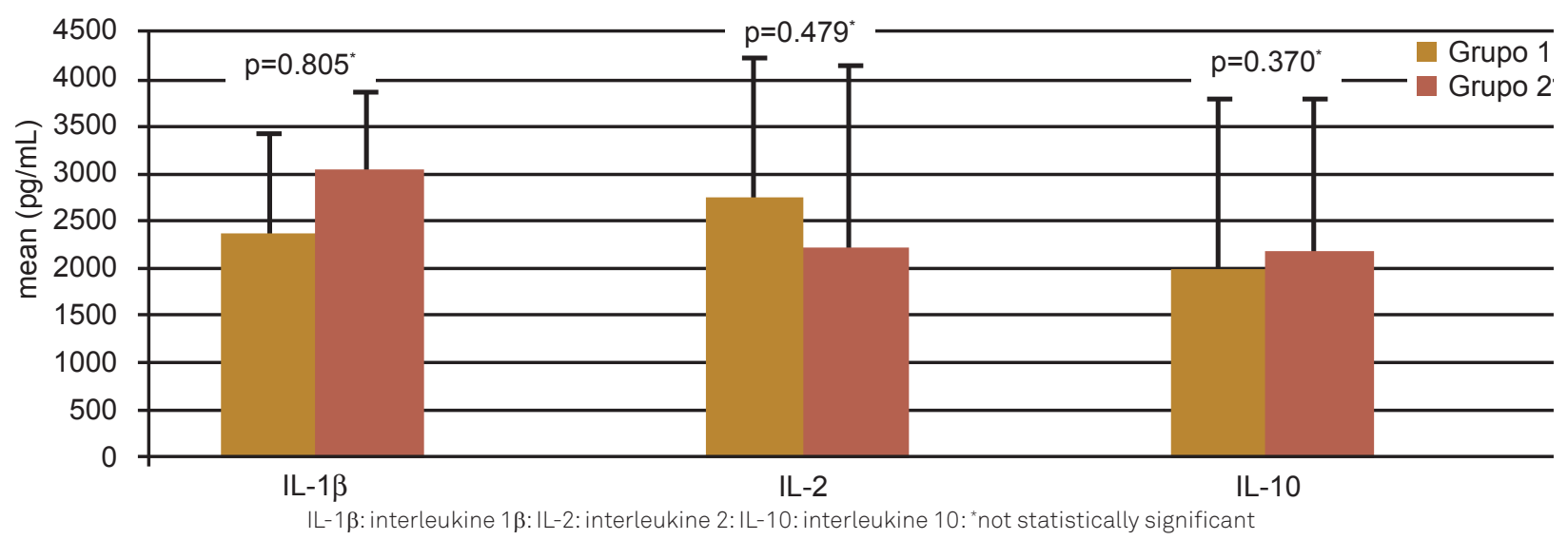

Figure 1. Comparison of interleukines $1 \beta, 2$ and 10 levels admission between groups 1 and 2. 

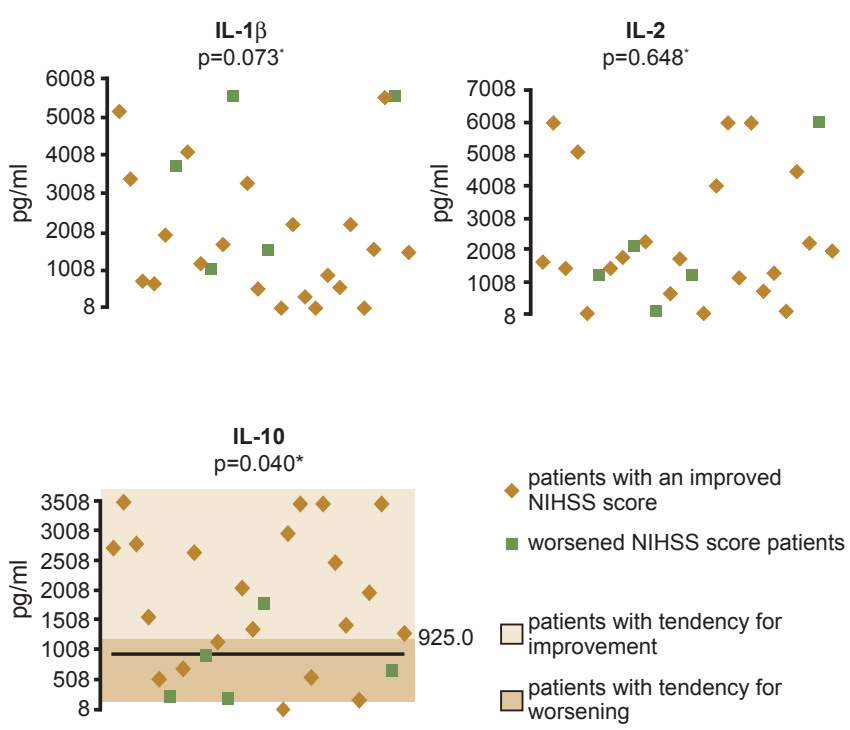

NIHSS: National Institutes of Health Stroke Scale.

Figure 2.Distribution pattern of patients from group 1 based on the variations in the NIHSS score during the first $72 \mathrm{~h}$ after ischemic stroke onset, upon arrival at the emergency room; improved: patients with reduction in NIHSS score; worsened: patients with increase in the NIHSS score; " not significant; ${ }^{* *}$ significant difference between patients with NIHSS score improvement and those with NIHSS score worsening regarding the IL-10 levels; according to the ROC curve, the cutoff value of IL-10 that represents the best relationship between sensitivity $(80 \%)$ and specificity $(76.2 \%)$ is $925.5 \mathrm{pg} / \mathrm{mL}$, i.e., patients with IL-10 higher than this cutoff value tend to have a better outcome during the first $72 \mathrm{~h}$ after ischemic stroke onset. stroke in different patients (NIHSS score between two and 36) can in part explain the diversity of the cytokine expression in our study. Also, the control subjects were not matched for atherosclerosis degree, sex or age. Taken together, these problems may account for the discrepancy between our data and the other studies where an increase in cytokine levels after stroke is reported ${ }^{2}$.

Substantial data demonstrate correlation between increased levels of IL-1 after ischemia and worsening of infarct severity ${ }^{2,3,14,15}$. In our study, we did not notice this correlation; however, we did find a significant correlation with IL-10 expression levels and neurological improvement. Our data regarding IL-10 is supported by other studies ${ }^{8}$. IL-10 provides a negative feedback mechanism by blocking the monocytes/ macrophage gene transcription to limit the production of proinflammatory cytokines, IL-6 and TNF-a, intercellular adhesion molecule-1 (ICAM-1), and matrix metalloproteinase (MMP). The involvement of IL-10 in the pathophysiology of ischemic neurological deterioration should be considered with caution, because to our knowledge, there are no studies defining the level and/or possible effect of IL-10 during neurological worsening. If the association between IL-10 levels and early neurological deterioration is confirmed, it is likely that administration of exogenous IL-10 during acute ischemic stroke can serve as a therapeutic strategy. Thus, this study gives additional evidence that IL-10 may have a potential role as a neuroprotector following acute ischemic stroke.

\section{References}

1. Dávalos A, Toni D, Iweins F, et al. Neurological deterioration in acute ischemic stroke: potential predictors and associated factors in the European cooperative acute stroke study (ECASS) I. Stroke 1999;30:2631-2636.

2. Wang $Q$, Tang $X N$, Yenari MA. The inflammatory response in stroke. J Neuroimmunol 2007;184:53-68.

3. Huang J, Upadhyay UM, Tamargo RJ. Inflammation in stroke and focal cerebral ischemia. Surg Neurol 2006;66:232-245.

4. Libby P. Inflammation in atherosclerosis. Nature 2002;420:868-874

5. Emsley HCA, Smith CJ, Gavin CM, et al. Clinical outcome following acute ischaemic stroke relates to both activation and autoregulatory inhibition of cytokine production. BMC Neurol 2007;7:5.

6. Simi A, Tsakiri N, Wang P, Rothwell NJ. Interleukin-1 and inflammatory neurodegeneration. Biochem Soc Trans 2007;35:1122-1126.

7. van Exel E, Gussekloo J, de Craen AJM, et al. Inflammation and stroke: the Leiden 85-Plus Study. Stroke 2002;33:1135-1138.

8. Vila N, Castillo J, Dávalos A, et al. Levels of anti-inflammatory cytokines and neurological worsening in acute ischemic stroke. Stroke 2003;34:671-675

9. Hanisch UK, Quirion R. Interleukin-2 as a neuroregulatory cytokine. Brain Res Brain Res Rev 1995;21:246-284.
10. Goldstein LB, Adams R, Alberts MJ, et al. Primary prevention of ischemic stroke: a guideline from the American Heart Association/ American Stroke Association Stroke Council: cosponsored by the Atherosclerotic Peripheral Vascular Disease Interdisciplinary Working Group; Cardiovascular Nursing Council; Clinical Cardiology Council; Nutrition, Physical Activity, and Metabolism Council; and the Quality of Care and Outcomes Research Interdisciplinary Working Group. Circulation. 2006;113:873-923.

11. Adams HP, Bendixen BH, Kappelle LJ, et al. Classification of subtype of acute ischemic stroke. Definitions for use in a multicenter clinical trial. TOAST. Trial of Org 10172 in Acute Stroke Treatment. Stroke 1993;24:35-41.

12. Sotgiu S, Zanda B, Marchetti B, et al. Inflammatory biomarkers in blood of patients with acute brain ischemia. Eur J Neurol 2006;13:505-513.

13. Tarkowski E, Rosengren L, Blomstrand C, et al. Intrathecal release of pro- and anti-inflammatory cytokines during stroke. Clin Exp Immunol 1997;110:492-499.

14. Muir KW, Tyrrell P, Sattar N, Warburton E. Inflammation and ischaemic stroke. Curr Opin Neurol 2007;20:334-342.

15. Boutin H, LeFeuvre RA, Horai R, et al. Role of IL-1 alpha and IL-1 beta in ischemic brain damage. J Neurosci 2001;21:5528-534. 